\title{
Pit to crack transition and corrosion fatigue lifetime reduction estimations by means of a short crack microstructural model
}

\author{
J.A. Balbín ${ }^{a}$, V. Chaves ${ }^{a}$, N.O. Larrosa ${ }^{\mathrm{b}, *}$ \\ ${ }^{a}$ Departamento de Ingeniería Mecánica y Fabricación, Escuela Superior de Ingeniería, Universidad de Sevilla, Camino de los Descubrimientos s/n, 41092 Sevilla, Spain \\ ${ }^{\mathrm{b}}$ Department of Mechanical Engineering, University of Bristol, Bristol BS8 1TR, England, United Kingdom
}

\section{A R T I C L E I N F O}

\section{Keywords:}

Fatigue strength

Pitting corrosion

Pit-to-crack transition

Short cracks

Micromechanical model

\begin{abstract}
A B S T R A C T
A microstructural model is presented to assess pit-to-crack transition and corrosion fatigue strength in pitted components in different environments. The model is first validated using available experimental data in the literature for pitting corrosion fatigue strength and S-N curves for both carbon and stainless steels. The value of the method proposed and its applicability is then shown by the development of fatigue knock down factor maps to the in-air S-N curve. Finally, the influence of pit local topology on pit-to-crack transition damage tolerance and the links to the NDE methods quantitative resolution necessary to account for defect shape or acuity in structural integrity assessments are discussed.
\end{abstract}

\section{Introduction}

Unlike general corrosion, where the rate of material removal is typically uniform, slow, and readily detected, pitting corrosion attack is by its nature localised, of rapid growth and represents a major challenge for state-of-the-art of non-destructive inspection techniques [1-3]. Localised corrosion affects most predominantly metals and alloys that have passive films, such as stainless steels and high strength aluminium alloys [4]. In carbon-steels, however, pitting can arise where there is a semi-protective film such as mill scale (formed during processing or welding), or due to microbiologically influenced corrosion (MIC) [5].

Under the influence of load, either monotonic or cyclic, pits may act as sites for crack initiation $[6,7]$, potentially leading to significantly shorter service lives $[8,9]$. Understanding the life limiting role of pitting in crack initiation and propagation is therefore relevant to a range of industries for (i) design; (ii) inspection and (iii) structural integrity assessment of components and structures operating in aggressive environments [7].

The design of components operating in harsh environments for very long durations is traditionally based on design codes. The traditional fatigue design approach uses environment-specific S-N curves or environmental penalty factors - knock down factors (KDF) or design fatigue factors (DFF) - to apply to the air/inert curve. Industry specific design codes and procedures have been developed to account for typical environments found in service. To name a few, BS EN ISO 19902 [10] and
DNVGL-RP-C203 [11] are used in Oil and Gas (O\&G) and Wind Offshore industries, EN13103 [12], EN13104 [13] or BS EN13261 [14] in the design of axles in railway industry and NUREG/CR-6909 [15] or ASME BPVC Section 3.2 [16] are used for designing in light water nuclear reactor and power generation environments. There remain uncertainty however on the origins of the penalty factors in relation to whether all factors contributing to the damaging mechanism (localised corrosion, pit-to-crack transition and propagation) have been fully considered [17]. Evidence shows that we as a community have not yet addressed corrosion fatigue properly. For example, cracks originating and propagating from corrosion pits may have been the main reason behind the failures in railway axles recently $[18,19]$

From an inspection viewpoint, one of the main challenges for NDE methods is to distinguish between sharp (e.g. fatigue) cracks and nonsharp defects and to discriminate those defects that are more severe [20] and to produce accurate descriptions. Recent NDE developments show promising opportunities for characterising defect acuity/shape. For instance, the concept of Full Matrix Capture (FMC) for ultrasonic applications [21], the application of data-fusion through modern ultrasonic array imaging techniques [22,23] and parametric-manifold mapping [24], among others. In any case, the detection of the earliest stages of pitting and cracking will remain challenging for state-of-the art NDE techniques applied, where a tradeoff between the ease of implementation and resolution is typically observed [25].

For structural integrity assessments, procedures like ASME B31G

\footnotetext{
* Corresponding author.

E-mail address: nicolas.larrosa@bristol.ac.uk (N.O. Larrosa).
} 
[26], API 579 [27] or DNV-RP-F101 [28] are used to evaluate the remaining strength of corroded components and structures. In API 579, pitting corrosion (Part 6) is dealt as local thinning and the standard recommends detailed analysis when there is insufficient toughness or if there is cyclic loading but gives little guidance on such analysis. When defects fail the geometry check, damage tolerance arguments (fracture mechanics) are then necessary and corrosion pits are assumed as crack-like defects. Methodologies using the pit size as an initial flaw size in LEFM calculations were also reviewed in [7] with some posterior contributions by other researchers $[29,30]$. It is also accepted that these methodologies are highly conservative in most cases.

Through pitting corrosion [31] and short crack initiation [32,33] and growth $[34,35]$ modelling, mechanistic insight could be gained on the relative importance of pit morphologies, environmental conditions and material microstructure in fatigue behaviour. This can be used to support design and integrity assessments as well as NDE methodologies, for the development of more realistic lifetime estimates and defect tolerance arguments.

Microstructure-sensitive models are undoubtedly a necessary pathway for mechanistic pit-to-crack transition analysis and the environmentally affected microstructure will play a fundamental role in the propagating (or non-propagating) behaviour of short fatigue cracks. These approaches can provide sufficient level of detail about the interactions of the many variables driving crack nucleation from localised corrosion. Within these approaches, crystal plasticity (CP) models are a well established computational tool for incorporating such microstructure attributes (grain size and morphology, texture, distribution of discontinuities, constituent particles, etc.) into a modelling framework and to determine the likelihood of short crack initiation that can eventually become propagating. The complexity of the experiments required (e.g. EBSD, X-CT, SEM) to develop CP models, the expertise required to calibrate, implement, post-process and analyse results make this type of approaches unattainable and impractical for most engineering applications at present, and only accessible to material scientists. Microstructural Fracture Mechanics (MFM) models, of significant less calibration, implementation and analyses complexity, have been proposed and used by several researchers since late 1980s $[34,35]$. These models have been applied extensively to explain short crack growth microstructure-dependence and to analyse engineering problems in which LEFM and EPFM concepts are inapplicable (e.g. the scale of cyclic plasticity and the crack tip process zone are of the size of the crack length and span a few microstructural barriers). For example, MFM has been used for analysing different variables on fatigue behaviour, such as grain size effect [36], shot peening effect [37], notch [38,39] and size effects [40], contact and residual stress fields effect [41], among other applications $[42,43]$. The methodology has been also used to analyse environment-assisted short fatigue crack growth and lifetime $[44,45]$. In this work, the significance of corrosion pits on the performance of engineering alloys will be assessed by means of the Navarro and de los Rios microstructural model [34] (NR model hereto). The micromechanical approach is integrated into a numerical framework that models the pit geometry, the crack and the microstructural barriers by means of distributed dislocations [46] and uses de Kitagawa-Takahashi diagram [47] to account for the effect of the environment on the material's microstructure resistance for short and long crack propagation. The methodology has been applied for evaluating the fatigue strength of pitted specimens and developing S-N curves for corrosion pits immersed in aggressive environments. The paper discusses the role of the pit global dimensions and geometry on fatigue strength and makes an effort to link this with the effective NDE resolution required to benefit from this type of advanced tools.

\section{Environmentally assisted microstructural short-crack growth model}

Although presented elsewhere $[38,40]$, the microstructural model developed by Navarro and de los Rios is briefly explained in this section. The model describes the interaction between growing short cracks and grain boundaries $[34,48,49]$ and assumes that there is no initiation period, i.e. the fatigue life of the material is consumed in the propagation of a short crack of the dimensions of one grain until failure.

The model accounts for the effectiveness of microstructural barriers to arrest cracks, defines the resistance of a material to fatigue loading as the minimum applied load to overcome all barriers and assumes that grains are of the same size and equally oriented. The crack driving force, that is the stress exerted at the grain boundary varies with stress level and crack length. Therefore, in the absence of stress raisers, once the crack overcomes the first microstructural barrier, the driving force is enough to propagate until failure. When the cracks arises from a stress concentration feature, there is a competing effect between stress and crack length. In this case, at the early stages of propagation, short cracks are subjected to high stress levels that become less severe as the crack grows. It is therefore possible that the local stress level at the crack tip surroundings is not enough to overcome a specific microstructural barrier.

\subsection{Short crack growth micromechanical model}

The NR model relies on the Distributed Dislocation Technique (DDT) to perform the representation of the problem of a short crack growing through the microstructure of the material $[46,50]$. The dislocations represent the strain nuclei necessary to evaluate the equilibrium equations that help to analyze the interactions of the crack with the microstructural barriers [51]. Fig. 1 shows the case of a crack growing in Mode I in an infinite plate and subjected to a cyclic stress amplitude $\sigma$. It is supposed the crack has spanned several grains through the plastic zone and reached the grain boundaries. The length of the crack is $2 a$, and is expressed in terms of the average grain size $D, a=i D / 2$. The variable $i$ represents the number of grains spanned by the crack and takes values $i=1,3,5, \ldots$. The microstructural barrier is modelled as a small region on length $r_{0} \ll D$, which might be the typical size of the grain boundary. The total length of the crack and the barrier is $2 c$, where $n=a / c$ is the normalised crack length. The crack and the barriers are modelled by means of a continuous distribution of dislocations with Burgers vector $b_{y}$ perpendicular to the crack line.

An existence condition can be used to calculate the stress $\sigma_{3}^{i}$ at the grain boundaries as a function of the remote applied stress $\sigma$. The details of how this is implemented in the scheme developed for the numerical
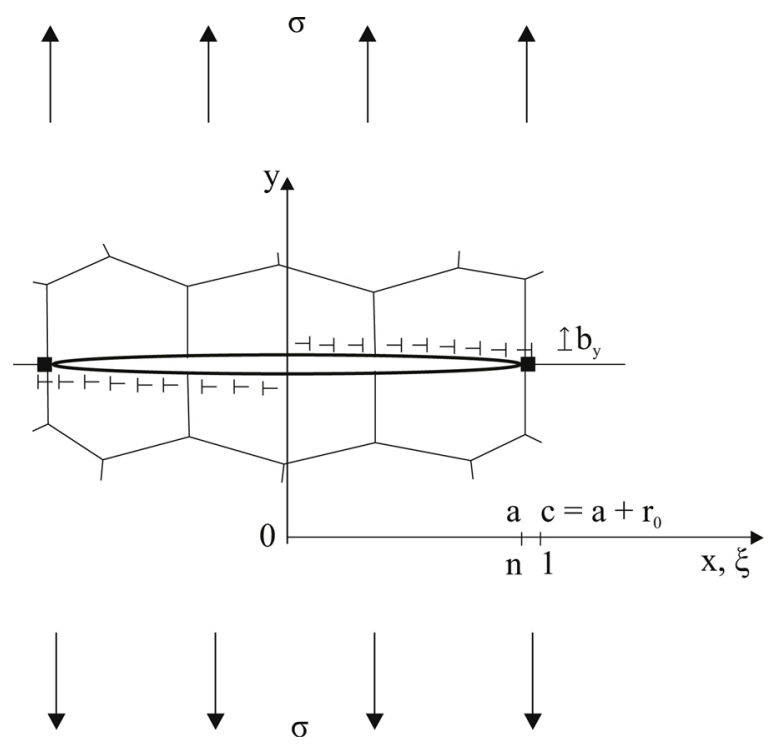

Fig. 1. Crack growing through the microstructure of the material in Mode I and modelled with distributed dislocations. 
integration of the dislocations equilibrium equation can be found in previous work $[52,38,40]$. For the problem of a crack in a semi-infinite medium (See Fig. 2) studied in this case, the existence condition can be solved and the maximum value of the stress at the barrier $\sigma_{3}^{i}$ is obtained as:

$\sigma_{3}^{i}=\frac{1.12}{\arccos (n)} \frac{\pi}{2} \sigma$

According to the NR model, the fatigue strength of the material, $\sigma_{F S}$, is then defined as the minimum external cyclic stress needed to overcome the first microstructural barrier, as other authors also noted [35, 53]. By introducing $\sigma_{F S}$ in Eq. (1), the strength of the first barrier $\sigma_{3}^{1 *}$, namely the critical value of the stress at which plastic slip is activated in the second grain, is obtained. Eq. (2) correlates the minimum applied remote stress $\sigma_{L i}$ necessary to overcome the ith barrier. As described in our previous work $[38,40], \sigma_{L i}$ is essentially the fatigue strength of the material as a function of crack length, i.e. the KT diagram of the material [47] in microstructural terms.

$\sigma_{3}^{i *}=\frac{1.12}{\arccos (n)} \frac{\pi}{2} \sigma_{\mathrm{Li}}$

In case the KT diagram of the material under analysis is not available, some approximation can be used. Among others [54,55], Vallellano et al. [56] proposed an equation to approximate the KT diagram of the material:

$\sigma_{\mathrm{Li}}=\sigma_{\mathrm{FS}} \frac{\sqrt{a_{0}}}{\left[(\mathrm{iD} / 2)^{j}+a_{0}^{j}-(D / 2)^{j}\right]^{\frac{1}{2 j}}}$

Where the parameter $a_{0}=\frac{1}{\pi}\left(\frac{\Delta K_{\mathrm{ht}}}{\Delta \sigma_{\mathrm{FS}}}\right)^{2}$ is the El Haddad parameter [54] and $\Delta K_{t h}$ is the long crack stress threshold intensity factor range. The exponent $j=2.5$ is valid for a wide range of materials [56].
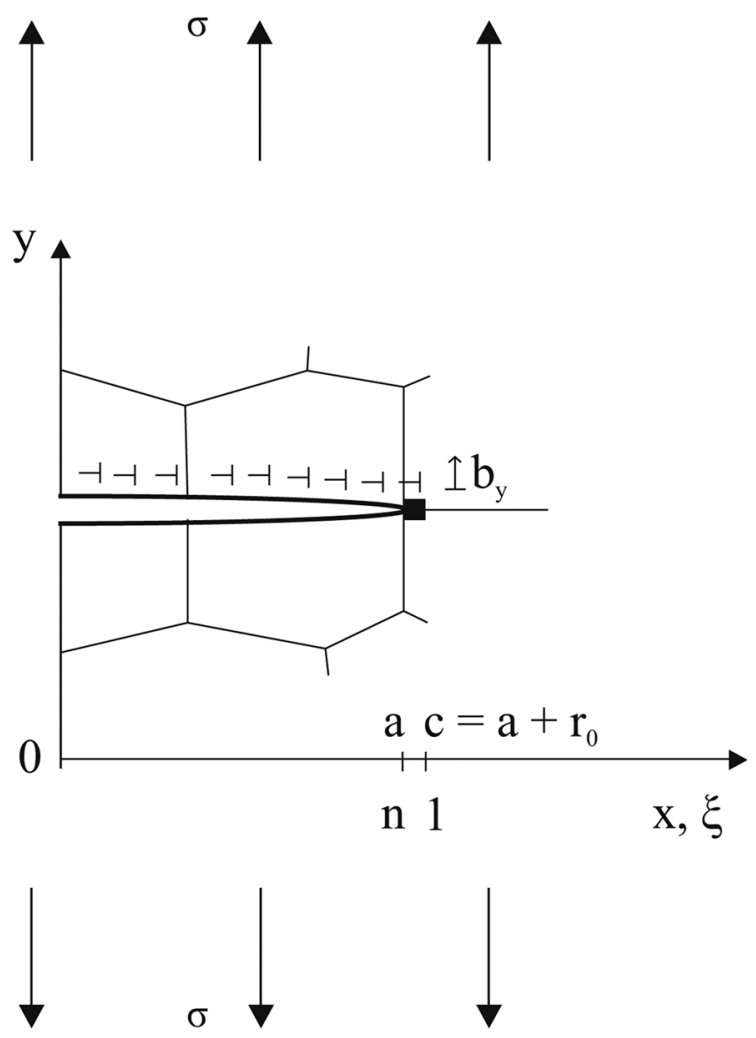

Fig. 2. Crack in semi-infinite medium growing through the microstructure of the material in Mode I and modelled with distributed dislocations.

\subsection{Application of the NR model to pitted components}

Fatigue cracks are initiated at corrosion pits, hence the analysis needs to include the pit geomtry effect. The 'far boundaries' of the component are considered to be relatively far away from the crack and the pit itself ('near boundaries'), thus their influence is neglected. The case of a crack near a free surface (semi-infinite case represented in Fig. 2) modeled by DDT has a known solution. For this reason, the procedure performed in this work consists on translating this case to that of a crack arising from a corrosion pit, that is, to make the geometry of the corrosion pit to be the free-surface, so that both the pit and the crack can be modeled by means of distributed dislocations. This makes possible to assess the short crack growth process taking into account the effect of the corrosion pit geometry through dislocations modelling and the agressive environment through the KT diagram.

The NR model is applied to analyse components having pitting corrosion defects. To do this, the following assumptions are made:

- The corrosion pit is assumed to be a two-dimensional smooth defect. Bidimensional theories for the solution of fatigue and fracture mechanics problems are popular because of their simplicity in comparison with their three-dimensional counterparts. These solutions involve the assumption of plane stress or plane strain states allowing a more tractable mathematical treatment of the problem. The effect of the surface roughness of the pit is implicitly considered by using the KT diagram of the material in the same environment.

- The pit acts as a stress concentrator, which means that the remote applied stress $\sigma$ produces a elastic stress gradient over the crack line, $\sigma_{y}(x)$, as shown in Fig. 3. The pit semi-width is $b$ and the pit depth is $\alpha$.

- The crack will initiate and grow from the bottom of the pit.

- The strength of the ith microstructural barriers (e.g. grain boundaries), $\sigma_{3}^{i *}$, is the same for the pitted and the plain component, and it just depends on the material-environment system.

$\sigma$
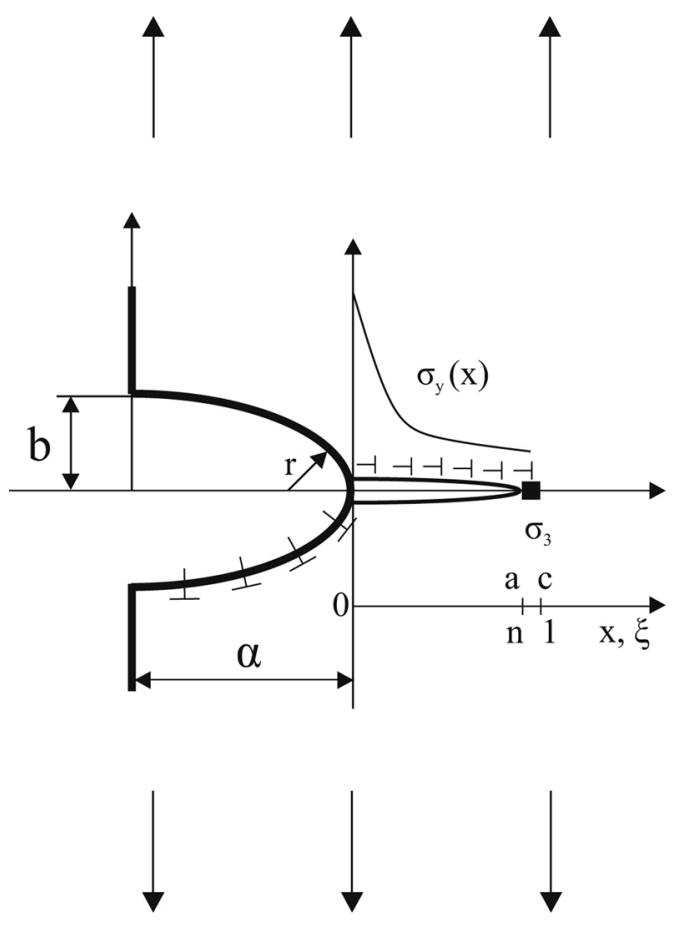

$\sigma$

Fig. 3. Pit profile and crack modeled by DDT. 
The methodology developed here builds on that established by Chaves et al. [39] to model notched geometries, where an explicit fundamental solution is not required and the solution for the dislocation in semi-infinite space can be used. The limitation of the approach proposed by Chaves et al. is that it needs an explicit mathematical description of the geometry. The numerical approach proposed by Larrosa $[57,58]$ is used in this work to generate the geometry of arbitrarily-shaped pits in order to easily build a wide range of parametric models and the numerical implementation of the equilibrium of dislocations allows the calculation of the resistance to dislocation movement $\left(\sigma_{3}^{i * P}\right)$ at every microstructural barrier ahead of an arbitrarily shaped pit. The computation of the minimum applied external stress $\sigma_{\mathrm{Li}}^{P}$ needed to overcome those barriers is explained next.

\subsection{Fatigue strength estimation for a pitted component}

An expression relating the micromechanical parameter $\sigma_{3}^{i *, P}$ to the macromechanical parameter $\sigma_{\mathrm{Li}}^{P}$ is needed. Eq. (2) express this relationship for the semi-infinite plain case. For the pitted specimen, the resistance to dislocation movement can be expressed in general terms as a function of the minimum applied external stress as:

$\sigma_{3}^{i *, P}=\Psi^{i} \quad \sigma_{\mathrm{Li}}^{P}$

where $\Psi^{i}$ is the solution given by the numerical method. Thus, as explained, by assuming that $\sigma_{3}^{i *, P}=\sigma_{3}^{i *}$ :

$\sigma_{\mathrm{Li}}^{P}=\frac{1.12}{\arccos (n)} \frac{\pi}{2} \frac{\sigma_{\mathrm{Li}}}{\Psi^{i}}$

If we approximate $\arccos n \approx[2(1-n)]^{\frac{1}{2}} \approx 2\left(r_{0} / \mathrm{iD}\right)^{\frac{1}{2}}$, then the following relationship is obtained for Eq. (5):

$\sigma_{\mathrm{Li}}^{P}=1.12 \frac{\pi}{4} \sqrt{\frac{\mathrm{iD}}{r_{0}}} \frac{\sigma_{\mathrm{Li}}}{\Psi^{i}}$

As shown in Eq. (5), the proposed methodology allows the prediction of the critical stress range for crack extension from localised defects, i.e. a pit-modified KT diagram accounting for the pit profile effect in a given environment. This approach enables pit-to-crack transition behaviour to be readily assessed. The pit-modified KT diagram is associated to the KT diagram of the material $\left(\sigma_{L i}\right)$ for the specific environment, microstructure $\left(i D / r_{0}\right)$ and geometry dependent variables $\left(\Psi^{i}\right)$.

Finally, the fatigue strength for a pitted specimen or component, $\sigma_{\mathrm{FS}}^{P}$, can be defined as the minimum external stress that is needed for the crack to overcome all the successive barriers, that is the maximum value of $\sigma_{\mathrm{Li}}^{P}$ calculated for all the successive crack lengths $(a=i D / 2)$ :

$\sigma_{\mathrm{FS}}^{P}=\max \left\{\sigma_{\mathrm{Li}}^{P}\right\} \quad i=1,3,5, \ldots$

\subsection{Algorithmic modelling of arbitrary shape pits}

Algorithmic modelling was used in this case to create the different pit geometries and generate the necessary input data for solving the DDT problem of the crack growing from the pit. The geometry of the pit is then parameterised making it possible to describe a wide range of pit designs. Thanks to the use of generative algorithms, all the parameters necessary to perform the numerical resolution of the equilibrium of dislocations $[38,40]$ are instantly obtained.

\section{Results}

\subsection{Model validation}

Here, pit-to-crack transition estimations using the proposed approach are reported and validated using experimental results provided in a report released by an EPRI-funded R\&D programme [59] associated with corrosion-fatigue of $12 \% \mathrm{Cr}$ and 17-4PH stainless steels steam turbine blades. These results were also analysed by Härkegård [60] and Schönbauer et al. [61] and comparisons with their predictions have also been performed. For the application of the model, spheroidal pitted specimens tested under ultrasonic fatigue conditions reported in [59] were analysed as semi-ellipsoids. The KT diagram of the material is approximated by means of Eq. (3), where the stress intensity factor thresholds and endurance limits used were those reported in [59]. The pit-modified KT diagrams for the different loading and environment conditions are presented in what follows.

First, fatigue strength estimations of spheroidal corrosion pits with those reported by Härkegård using a so-called modified El Haddad shortcrack model are presented. The relevant $12 \% \mathrm{Cr}$ stainless steel properties in air at $90^{\circ} \mathrm{C}$ are shown in Table 1 for stress ratios $R=0.05,0.5$, 0.8 . The ultimate tensile strength are 767 and $723 \mathrm{MPa}$ and hardness HV250 and HV235 for the two batchs of stainless steel tested, respectively. The reported average grain size for this material is $6 \mu \mathrm{m}$. For all pits considered, the semi-width-to-depth ratio is 0.5 . In this case, 37 different pit geometries were analysed using the proposed approach.

Fig. 4 shows comparisons of the predictions made by Härkegård (dashed line) and the micromechanical model presented in this work (continuous line) with the experimental results reported in [59]. It is observed that the micromechanical model estimations captures the pit size, in terms of semi-width $b$ (see Fig. 3), and stress ratio effects and that results are in good agreement with experimental results. The predictions of the micromechanical model are higher than those obtained with the modified El Haddad short-crack model. Estimations for $R=0.5$ and $R=0.8$ are in better accordance with laboratory tests than predictions for $R=0.05$. The differences between the experimental and the estimated values are shown in Fig. 5, where it can be seen that all failures are within $\pm 20 \%$ error band. It is worth mentioning that estimations for $R=0.5$ and $R=0.8$ are within $\pm 10 \%$ error.

Schönbauer et al. performed ultrasonic fatigue tests $(20 \mathrm{kHz})$ using specimens made of $17-4 \mathrm{PH}$ stainless steel under two different stress ratio ( $R=0.05$ and $R=0.4$ ) at $90^{\circ} \mathrm{C}$ air and aerated $10,000 \mathrm{ppm} \mathrm{Cl}^{-}$solution. The ultimate tensile strength is $1034 \mathrm{MPa}$ and the hardness is $335 \mathrm{HB}$ and $339 \mathrm{HB}$ at room temperature, as reported by the authors. This allowed these researchers to study crack growth in the threshold regime which for $>10^{9}$ cycles is extremely time-consuming. For this study, single corrosion pits with controlled depth were generated in the gauge length of fatigue specimens using a droplet cell technique [62]. The created pit depth was $100 \mu \mathrm{m}$ and $250 \mu \mathrm{m}$ with an approximate semi-width-to-depth ratio of 0.8 . In this case, 30 different pit geometries were analysed using the proposed approach. The material properties are shown in Table 2 and the reported average grain size is $6 \mu \mathrm{m}$.

Fatigue strength estimations as a function of the pit depth are compared in Fig. 6 with those reported by Schönbauer et al. using ElHaddad approach (dashed lines) and experimental results. It can be seen that estimations are very close to experimental tests and that in all cases estimations are conservative. The predicted curves also captures the differences in 'failures' and 'run-outs', where 'failures' should lay in or above the predicted lines and run-out points should sit below this line. Fig. 7 shows the difference between estimations and experimental fatigue strength results. With different levels of accuracy, the graph shows that estimations are conservative in all cases (only 'failures' considered), where most cases are within the $+20 \%$ error band.

Please note that all the fatigue strength predictions obtained for the comparisons with the works of Härkegård and Schönbauer are expressed

Table 1

$12 \% \mathrm{Cr}$ stainless steel $\left(90^{\circ} \mathrm{C}\right.$ air) properties for different stress ratios assessed by Härkegård [60].

\begin{tabular}{llll} 
Stress ratio $R$ & 0.05 & 0.5 & 0.8 \\
Fatigue strength range, $\Delta \sigma_{F S}(\mathrm{MPa})$ & 640 & 370 & 150 \\
$\Delta K_{t h}(\mathrm{MPa} \sqrt{m})$ & 3.8 & 2.7 & 2.2 \\
\hline
\end{tabular}




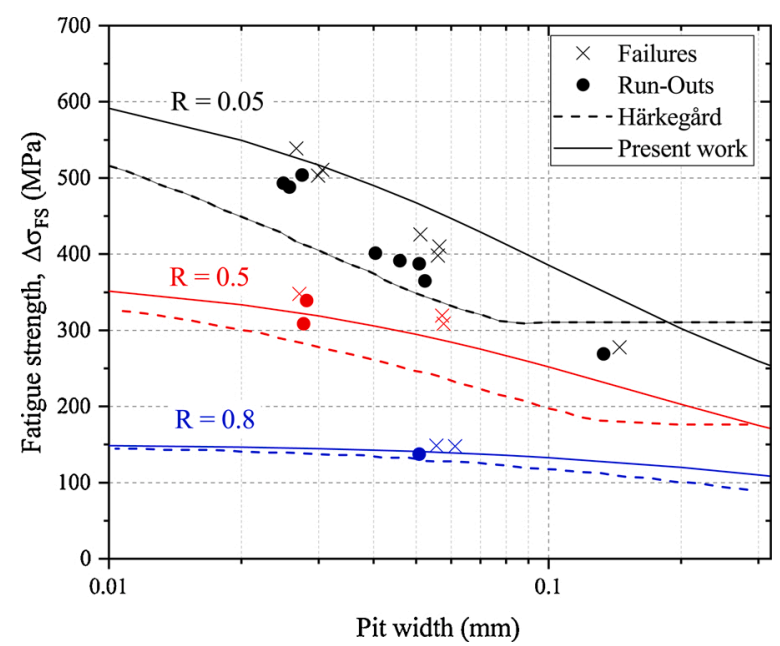

Fig. 4. Fatigue tests results of $12 \% \mathrm{Cr}$ stainless steel specimens analysed by Härkegård [60]. Estimations with present method.

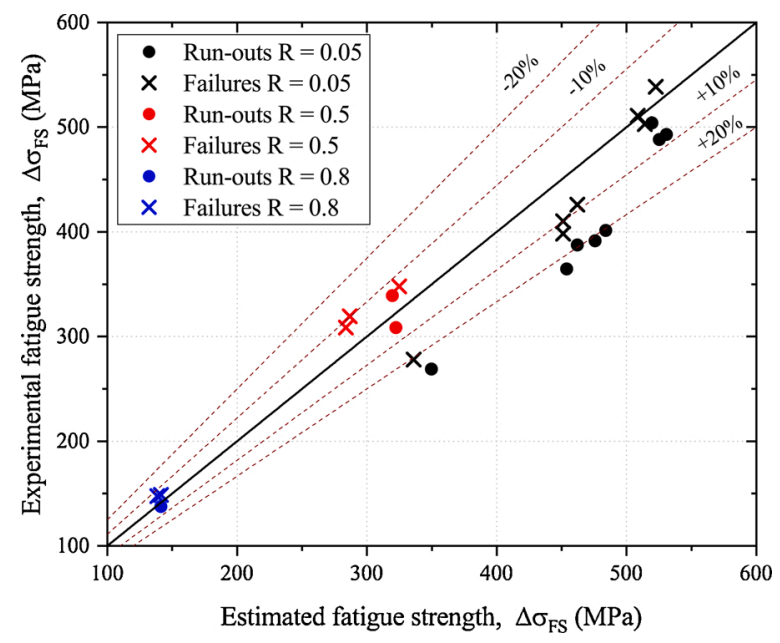

Fig. 5. Comparison between experimental and estimated fatigue strength related to fatigue tests of $12 \% \mathrm{Cr}$ stainless steel specimens analysed by Härkegård [60].

Table 2

17-4PH stainless steel properties for different stress ratios and environments evaluated by Schönbauer [61].

\begin{tabular}{llll}
\hline Stress ratio $R$ & 0.05 & 0.4 & 0.4 \\
Environment & $90^{\circ} \mathrm{C}$ air & $10,000 \mathrm{ppm} \mathrm{Cl}^{-}$ & $90^{\circ} \mathrm{C}$ air \\
Fatigue strength range, $\Delta \sigma_{F S}(\mathrm{MPa})$ & 760 & 431 & 589 \\
$\Delta K_{t h}(\mathrm{MPa} \sqrt{\mathrm{m}})$ & 3.28 & 1.61 & 2.60 \\
\hline
\end{tabular}

as ranges (in text, figures and tables), as given by the authors in each independent work.

\subsection{Estimation of $S-N$ curves and knock-down factors}

In the previous section, the proposed method was used to evaluate pit-to-crack transition for corrosion pits in stainless steel for two different environments by means of a parametric analysis, where a wide range of defect geometries was considered.

There is uncertainty about the shape of defects that are detected using NDE techniques and its effect on load bearing capacity. Limited information is obtained from NDE data and in the most optimistic scenario, three orthogonal dimensions (depth, width, length)can be used

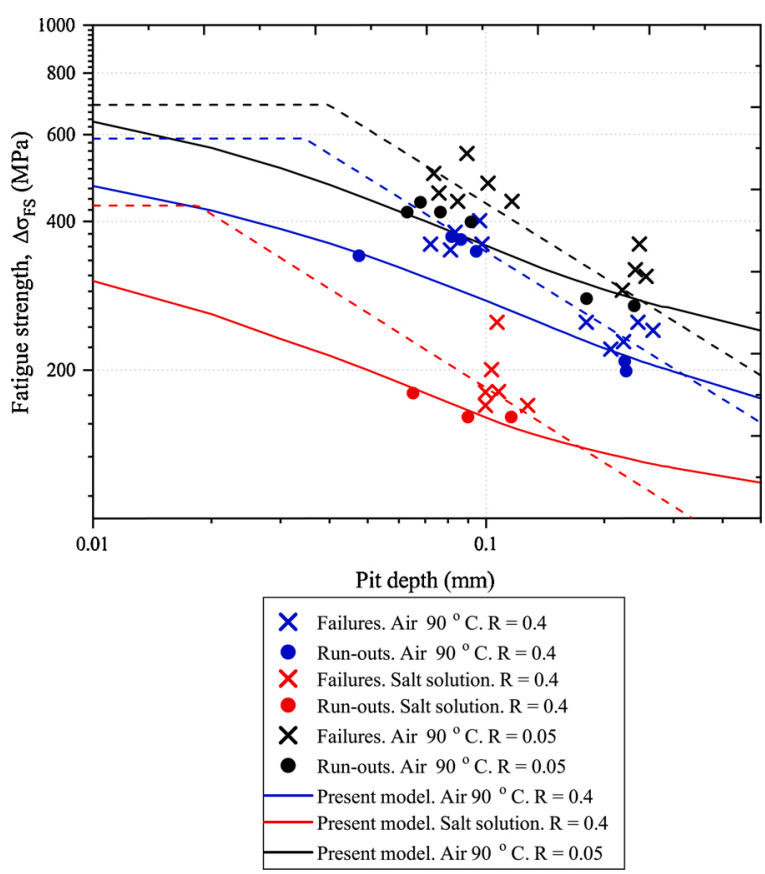

Fig. 6. Fatigue tests results of $17-4 \mathrm{PH}$ stainless steel specimens analysed by Schönbauer et al. [61]. Estimations with present method.

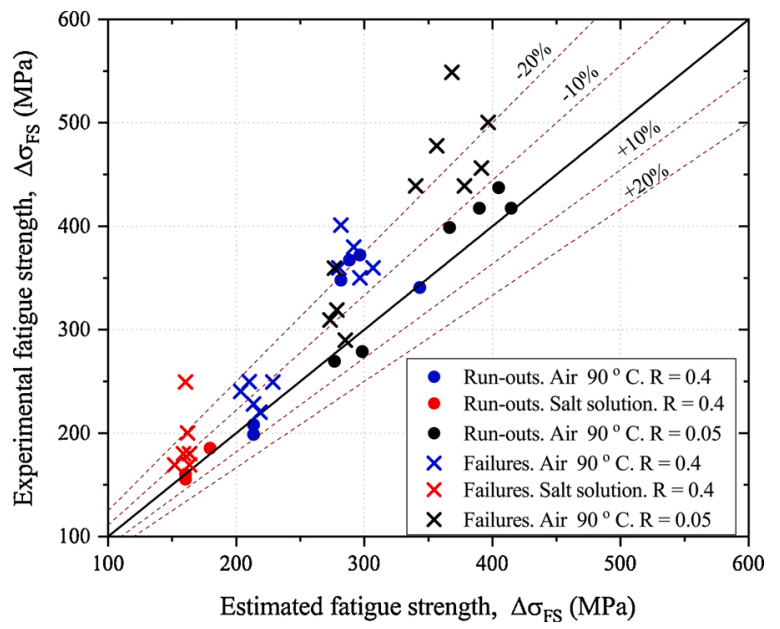

Fig. 7. Comparison between experimental and estimated fatigue strength related to fatigue tests of $17-4 \mathrm{PH}$ stainless steel specimens analysed by Schönbauer et al. [61].

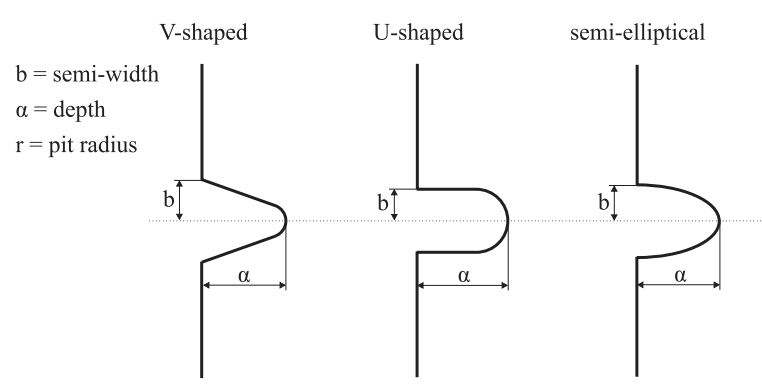

Fig. 8. Sketch of three different shapes of superficial defects. 
for characterising the severity of detected anomalies.

To show the value of the proposed approach, we will evaluate the effect of the pit shape on pit-to-crack transition by performing a largescale parametric analysis. The fatigue strength for each case was evaluated and expressed in the form of knock-down factors (KDF), i.e. the ratio between the fatigue strength of the pitted specimen and the fatigue strength of plain specimen for the specific environment. The method was applied to three different pit geometries and validated with experimental data for a carbon steel and for the 17-4PH stainless steel analysed in the previous section. Please note that the microstructural model used in this work only considers the presence of a single pit and a single crack. In reality, it might be the case that more than one corrosion pit could develop in a mechanical component [63]. Several cracks may be able to initiate from each pit as well. Some of these cracks may be arrested at microstructural barriers. Some other cracks may grow and coalesce and the rest of the cracks may initiate and grow independently, especially early in the growth process where multiple short cracks may be in competition with each other on different planes. We postulate that there will be only one crack leading to failure.

The material properties used for the carbon steel were those published by Li and Akid [64] in air and artificial seawater $(R=-1)$. The maximum tensile strength for this carbon steel is $610 \mathrm{MPa}$. The authors reported the experimental KT diagram in both environments. The average grain size of the material is $10 \mu \mathrm{m}$ and the relevant material properties are detailed in Table 3.

Estimations of the influence of the pit geometry and the environment on the fatigue strength have been carried out using the micromechanical model. The pit depth $\alpha$ and the semi-width $b$ have been used to describe the corrosion pit geometries, as shown in Fig. 8. Three types of superficial pit geometry have been studied, namely V-shaped, U-shaped and semi-elliptical pits.

- V-shaped pits. This type of geometry is different from the rest because the pit radius, $r$, is independent of the rest of the geometrical parameters and also needs to be defined. Therefore, the proposed geometry called V1-shaped is defined by a pit radius $r$ which is, in relation to pit semi-width $b$, equivalent to $25 \%$.

- U-shaped pits. In the case of U-notch, only the semi-width-to-depth ratio $b / \alpha$ is studied from 0.1 to 1 , since if the notch is wider than deep it loses the geometrical condition of being a $U$ and would become a type of ellipse. That is the reason why it is shown only half plot in U-shaped estimations.

- Semi-elliptical pits. The construction of the ellipse is interesting because both parameters, $\alpha$ and $b$ are related around the pit radius, which is done automatically by algorithmic modelling.

In this case, 460 different pit geometries were analysed, with pit depth $\alpha$ values varying from $0.05 \mathrm{~mm}$ to $2 \mathrm{~mm}$ and pit semi-width-todepth ratio $b / \alpha$ from 0.1 to 2 . By doing this, we are able to model defects with varying acuity. The analysis has been focused on the shape of the defect, that is, the role of the pit depth and the pit semi-width, since they are the representative variables typically obtained from NDE inspections of engineering components and structures [65].

Fig. 9-11 show estimations for the different pit geometries and the different environments considered as colour maps. This kind of representation is helpful for readily analysing the influence of corrosion pits on fatigue strength and comparing different environments. The colour map shows the KDF which is defined as the relation between the fatigue

Table 3

Material properties $(R=-1)$ for carbon steel in different environments. Tests done by Shu-Xin Li and Akid [64].

\begin{tabular}{lll}
\hline Fatigue environment & $\Delta K_{\text {th }}(\mathrm{MPa} \sqrt{m})$ & Fatigue strength amplitude, $\sigma_{F S}(\mathrm{MPa})$ \\
\hline Air & 5.94 & 279 \\
Artificial seawater & 4.56 & 126 \\
\hline
\end{tabular}

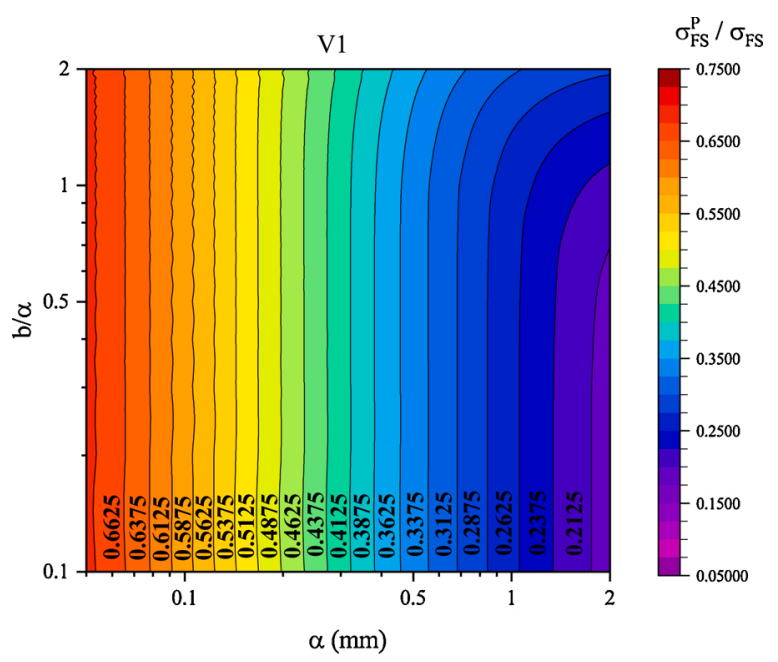

(a) Common air environment

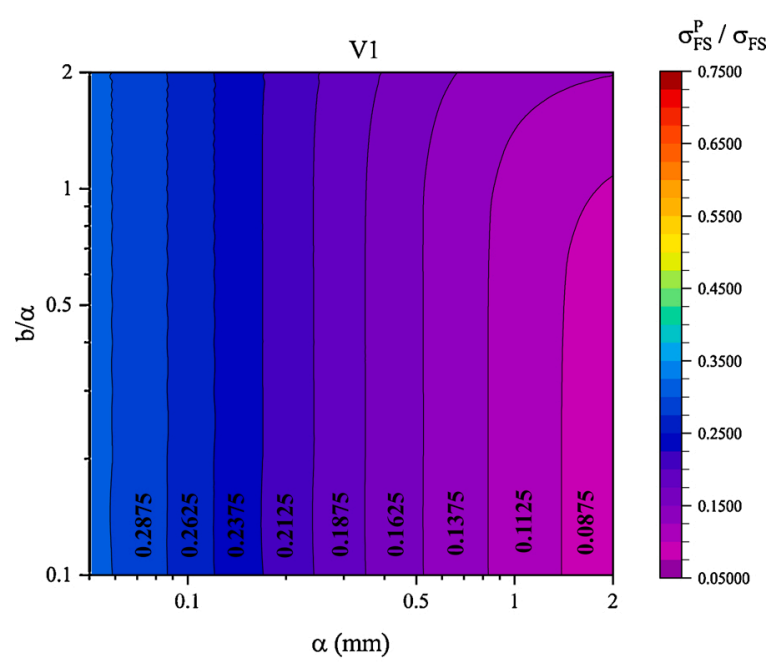

(b) Corrosive environment

Fig. 9. Knock down fatigue factor for V1-shaped pits as a function of pit depth $(\alpha)$ and pit aspect ratio $(\alpha / b)$ in $\log$-log scale. Material: carbon steel in different environments [64]. (For interpretation of the references to colour in the text, the reader is referred to the web version of this article.)

strength estimation in the presence of a pit, $\sigma_{\mathrm{FS}}^{p}$, and the plain fatigue strength of the material in a non-aggressive environment, $\sigma_{F S}$. The resolution of the colour code scale is 0.025 . Average values of each range of the colour code scale are included in the plots for the sake of clarity.

Each single plot can be seen as a map in which the pitted fatigue strength of the component can be evaluated based on the defect dimensions, assuming an specific shape, and environment conditions. By applying the corresponding KDF of the environment of interest to the plain fatigue strength of the material (in the non-aggressive environment), the evaluation of the fatigue strength of the material for such environment can be obtained.

Several observations may be made from the figures. First, there exists a depth - controlled (D) zone that spans the whole aspect-ratio range of values for relatively small pits $(<0.2 \mathrm{~mm})$ and reduces with pit-depth to only small pit aspect-ratios. In this zone, the influence of the pit aspect ratio is negligible and the fatigue strength is mainly controlled by the pit depth. There is a transition zone of mix - dependency (M), where both parameters have a shared effect on fatigue strength. Finally, an aspectratio controlled (A) zone can be distinguished, where the fatigue strength is weakly dependant on the pit depth and mainly controlled by the aspect-ratio of the defect. This area extends the most for higher aspectratio values (i.e. blunt defects). An example of the location of these three 


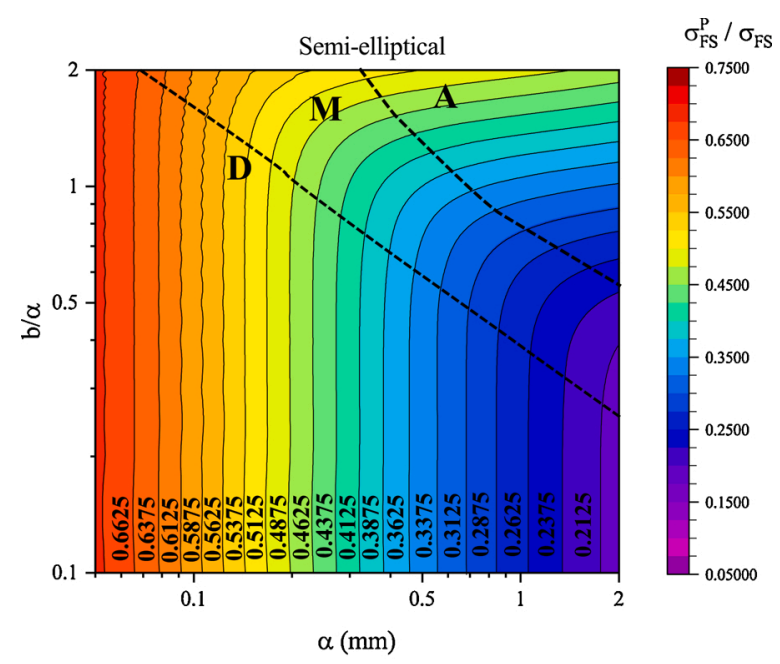

(a) Common air environment

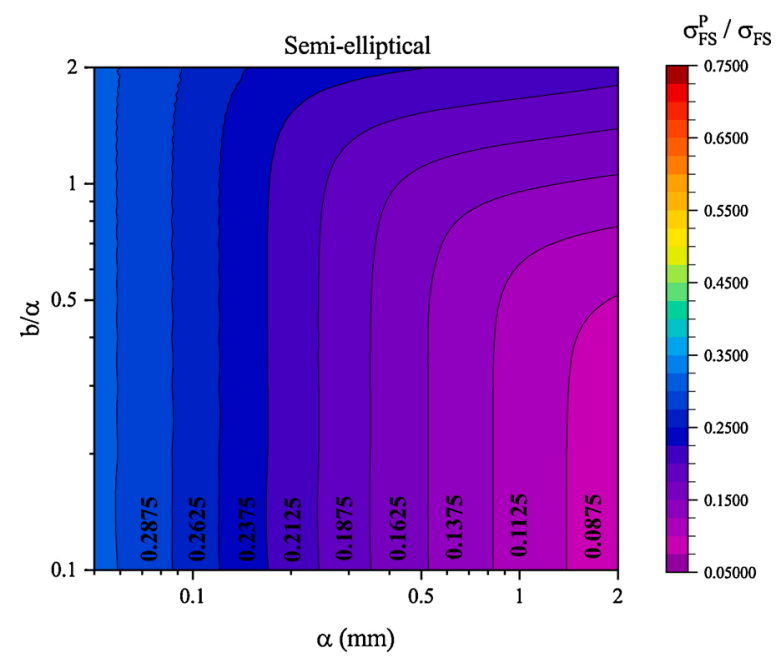

(b) Corrosive environment

Fig. 10. Knock down fatigue factor for semi-elliptical pits as a function of pit depth $(\alpha)$ and pit aspect ratio $(\alpha / b)$ in log-log scale. Material: carbon steel in different environments [64]. (For interpretation of the references to colour in the text, the reader is referred to the web version of this article.)

zones is shown in Fig. 10a. For the sake of clarity, the simple way to proceed with the approximate division of the graph in the three different zones is based, qualitatively, on the change in the slope of the line that divides between two different coloured regions. In this way, two black dashed lines have been drawn, one corresponding to the points where the practically vertical slope is lost and the other corresponding to the points where the lines begin to present a slightly horizontal slope.

Defect acuity is implicitly considered in these graphs and affects the level of stresses/strains and the extension of the defect area of influence. Hence, it has a strong impact on the fatigue performance of the material. Instead of focusing on the defect tip acuity, the approach proposed in this work use the global geometry dimensions, $\alpha$ and $b / \alpha$, to evaluate fatigue performance as these are typically obtained during NDE inspections. It is important to note that a defect shape needs to be assumed. Crack sizing in pitting corrosion cases is a difficult task, so the worst and best case scenario could be accounted for in terms of the nonpropagating crack length. The maximum value of stress $\sigma_{\mathrm{Li}}^{N}$ defines the largest non-propagating crack that the pitted component could tolerate. For this reason, an example of the evolution of stresses $\sigma_{\mathrm{Li}}^{N}$ as a function of crack length is shown where several pit geometry ratios, $b / \alpha$, have been analysed in Fig. 12 for a $1 \mathrm{~mm}$ depth semi-elliptical deffect. The black curve shows the increase of the maximum non-propagating crack

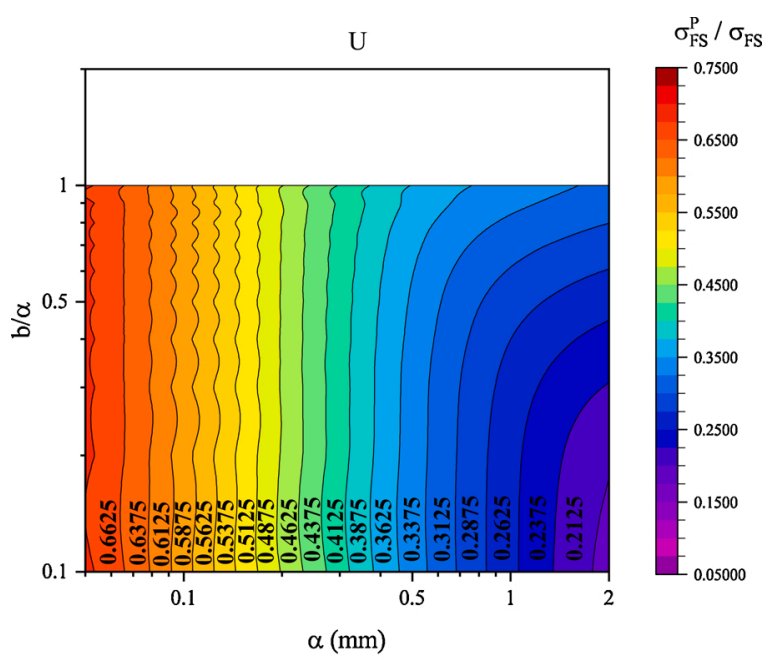

(a) Common air environment

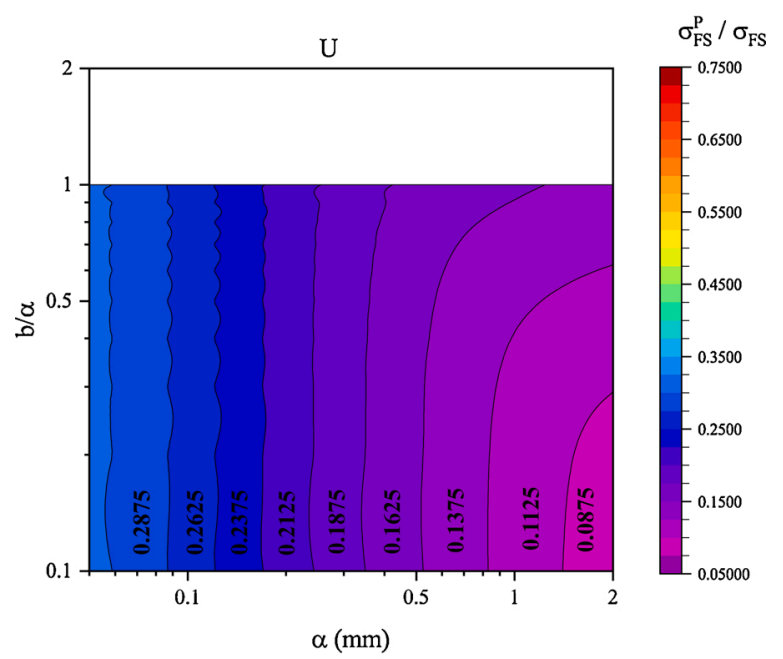

(b) Corrosive environment

Fig. 11. Knock down fatigue factor for U-shaped pits as a function of pit depth $(\alpha)$ and pit aspect ratio $(\alpha / b)$ in log-log scale. Material: carbon steel in different environments [64]. (For interpretation of the references to colour in the text, the reader is referred to the web version of this article.)

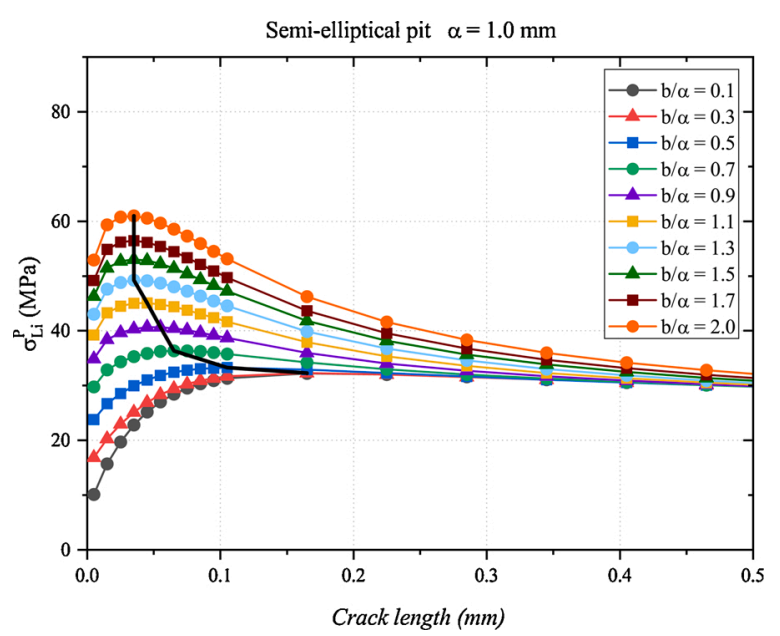

Fig. 12. $\sigma_{\mathrm{Li}}^{P}$ stress amplitude values as a function of crack length. Material: carbon steel in aggressive environment [64]. 
length with decreasing defect acuity. The range of crack lengths $(<0.17 \mathrm{~mm})$ represented by the black curve are outside the resolution of any available NDE technique. A conservative assumption for fatigue assessments would be to consider cracks of $0.17 \mathrm{~mm}$ or larger as this would give lower bound endurance limit values. For the case under analysis, the longest non-propagating crack lengths $(0.17 \mathrm{~mm})$ are found for $b / \alpha \leq 0.5$. For shallow pits $(b / \alpha>1.0)$, crack initiation from the pit bottom is more difficult to occur as reported by Turnbull et al. [66] and Larrosa $[7,67]$.

In addition to the three geometries described above, two more Vshaped geometries have been analysed, labelled as V2 and V3. The pit radius for $\mathrm{V} 2$ and $\mathrm{V} 3$ is $50 \%$ and $75 \%$ of the pit semi-width $b$, respectively. Comparisons of the relative effect of the defect shape on the KDF value for fixed depth are shown in Fig. 13, where the effect of the environment can be appreciated. As pointed out previously, the effect of the aspect ratio on the KDF is small for small values of $b / \alpha$ for all the cases under analysis. In particular for V1, with the smallest tip radius, the KDF value remains almost constant for the whole range of aspect ratios analysed - about $\sigma_{\mathrm{FS}}^{P} / \sigma_{\mathrm{FS}}=0.32$ for air and $\sigma_{\mathrm{FS}}^{P} / \sigma_{\mathrm{FS}}=0.15$ for the aggressive environment.

As shown in Fig. 13, for sharp pits (low $b / \alpha$ ) the KDF value coincides for all the different cases. V-shaped pits provide lower-bound KDF estimates where, as expected, the pit tip acuity dominates the fatigue behaviour. As expected, blunter pits, i.e. of higher pit tip radius, the KDF increases. On the contrary, estimations for the semi-elliptical pit result in upper-bound KDF values. To show the influence of the geometrical parameters of the analysed pit geometries, the $K_{t}$ factor of each case has been calculated using the solution of the stress concentration factor of an elliptical hole in an infinite plate, $K_{t}=1+2 \sqrt{\alpha / r}$, based on the pit depth $\alpha$ and pit radius $r$ of the different geometries. Fig. 14 shows the evolution of the KDF as a function of $K_{t}$ factor for two specific pit depths. The most relevant feature that can be extracted from this graph is that it is effectively corroborated that the most determining parameters for evaluating fatigue strength are the pit depth and the pit radius as confirmed from the small difference between the three pit shapes. The figure also shows that the equation for the $K_{t}$ for the elliptical hole can also be used to describe the $K_{t}$ of V-notches and U-notches (which are ultimately a special case of V-notches). Furthermore, the figure confirms that both the $K_{t}$ and the defect depth are necessary to account for the effect of the pit on fatigue strength.

Additionally, Fig. 15 shows the pitted fatigue strength (for a given pit depth) as a function of the stress concentration factor, $K_{t}$, calculated by means of the finite elements method. Results are shown for a carbon steel for both inert and aggressive environments [64]. It is observed that the crack-like behaviour in the corrosive environment spans to lower

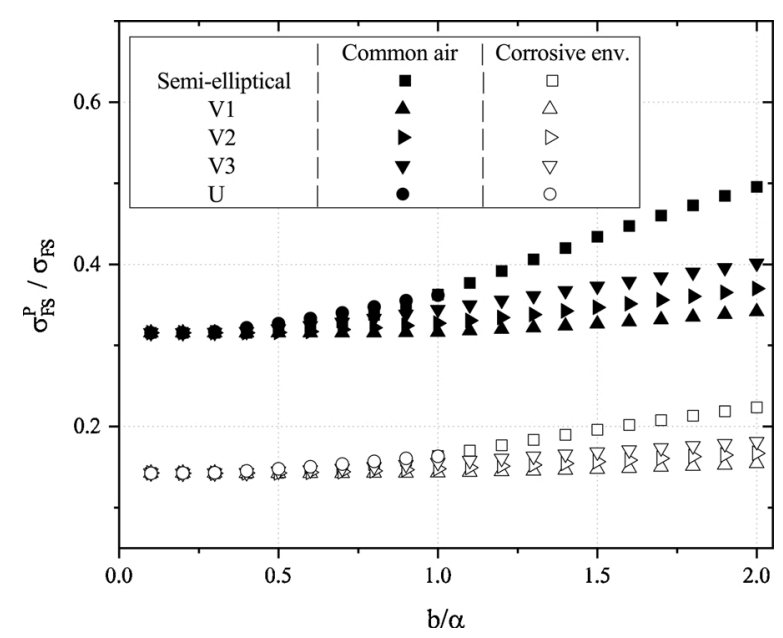

Fig. 13. Knock down factor values for pit depth $\alpha=0.6 \mathrm{~mm}$. Material: carbon steel [64].

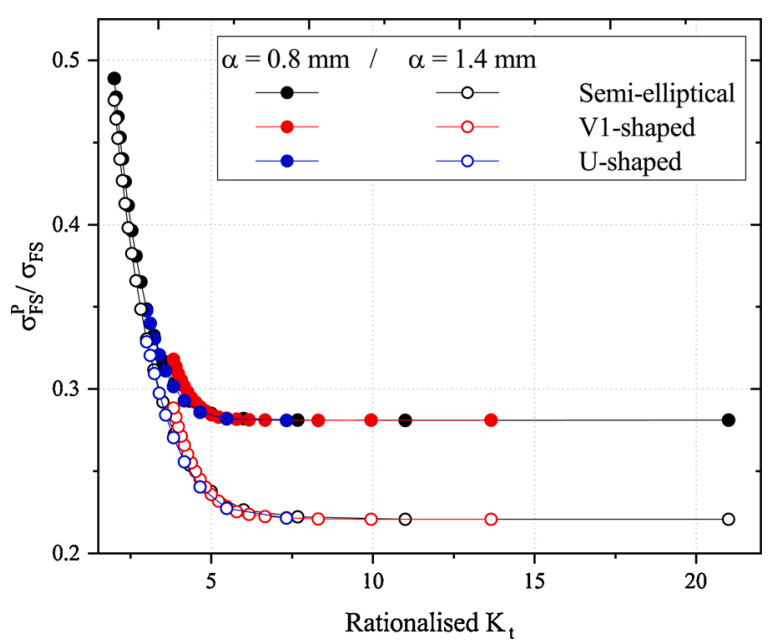

Fig. 14. In-air knock down factor as a function of rationalised $K_{t}$. Material: carbon steel specimens [64].

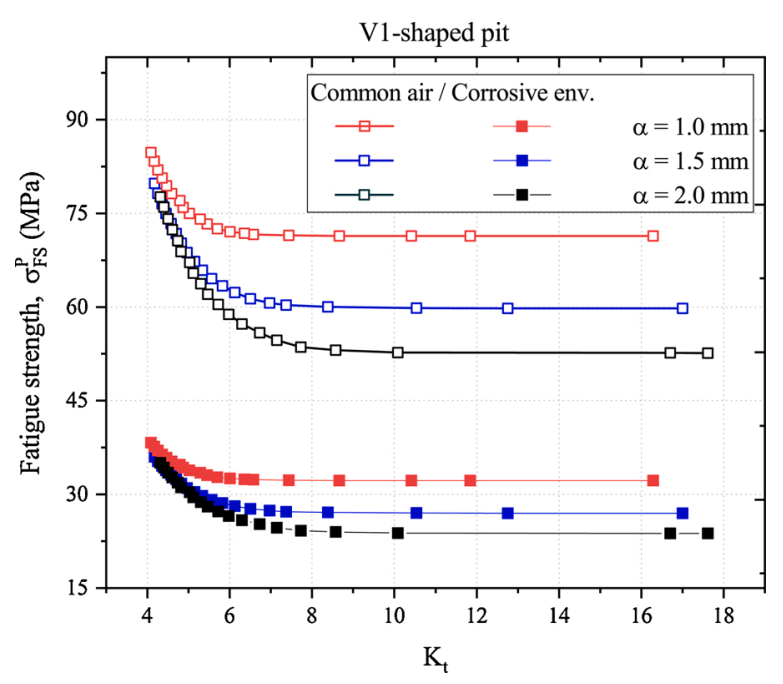

Fig. 15. V1-shaped fatigue strength amplitude as a function of the stress concentration factor. Material: carbon steel inside inert and aggressive environments [64].

values of $K_{t}$, in comparison to common air, i.e. the curves in the corrosive environment flattens.

To gain more insight on the V-shaped pits, a parametric analysis has been performed to understand the joint effect of pit depth, pit aspectratio and pit tip acuity. Fig. 16 shows the KDF estimations as a function of the dimensionless pit radius $(r / b)$, for a range of pit radii that spans from $5 \%$ to $75 \%$ of the pit semi-width $b$ and 3 different pit depths and 4 aspect-ratios.

The vertical dotted line represents a general estimation of the pit radius value below which the fatigue endurance is almost insensitive to pit tip acuity $(r / b<0.2)$. Larger differences are observed for deeper, blunt pits (max. difference is $9.78 \%$ for $\alpha=2 \mathrm{~mm}$ and $b / \alpha=1$ ). Therefore, lower bound fatigue strength estimations are obtained for $r / b<0.2$ for specific pit global dimensions ( $\alpha$ and $b$ ). In other words, the pit severity is almost identical to that of the sharp V-shaped pit $(r / b=0)$. The effect of the pit tip radius becomes more significant for higher values of pit radii $(r / b>0.2)$. To benefit from this in structural integrity assessments, accurate NDE characterisation of pits acuity is crucial.

We can estimate the minimum NDE resolution that is necessary to support structural integrity arguments based on pit acuity. For example, let us assume that pits of varying aspect ratios $(b / \alpha=0.25-1)$ are found 


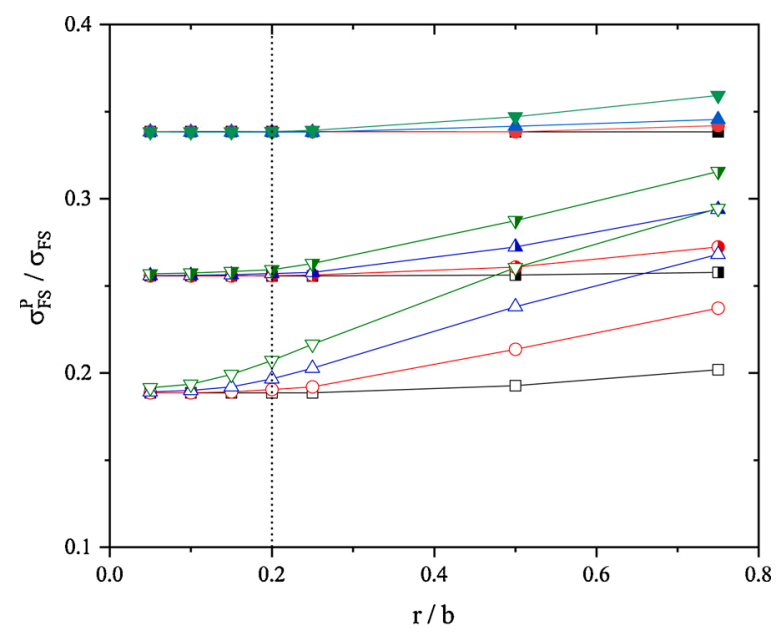

\begin{tabular}{|c|c|c|c|c|}
\hline$\alpha(\mathrm{mm})$ & $\mathrm{b} / \alpha=0.25$ & $\mathrm{~b} / \alpha=0.5$ & $\mathrm{~b} / \alpha=0.75$ & $\mathrm{~b} / \alpha=1.0$ \\
\hline 0.5 & $\because$ & $\longrightarrow$ & $\boldsymbol{\Delta}$ & $\nabla$ \\
\hline 1.0 & $\square-$ & -1 & $\Delta$ & 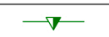 \\
\hline 2.0 & $\square$ & 0 & $\Delta$ & $\nabla$ \\
\hline
\end{tabular}

Fig. 16. In-air knock down factor as a function of dimensionless pit radius for V-shaped pitted carbon steel specimens [64].

in a structure operating in an aggressive environment, where the maximum pit depth is $2 \mathrm{~mm}$. Conservatively, from Fig. 16 it can be argued that the values of $r / b$ that will make a difference in pitting fatigue strength for $b / \alpha=0.25$ and $b / \alpha=1$ are $r / b \geq 0.5(r \geq 0.0625 \mathrm{~mm})$ and $r /$ $b \geq 0.1$ ( $r \geq 0.20 \mathrm{~mm})$, respectively. Unfortunately, values of pit radius $r \leq 1.0 \mathrm{~mm}$ are typically outside the resolution of most current in-field state-of the-art NDE techniques. However, resolving defects with $r>1.0 \mathrm{~mm}$ will allow benefit to be accounted for in fatigue assessments where the sharp tip assumption may be excessively conservative. As shown in Fig. 17, the value of KDF for pit radii below $0.2 \mathrm{~mm}$ could be approximated to $0.34,0.25$ and 0.18 for pit depths $0.5,1.0$ and $2.0 \mathrm{~mm}$, respectively.

Finally, the proposed approach has been sued to generate environment-specific S-N curves estimates. The process consists on

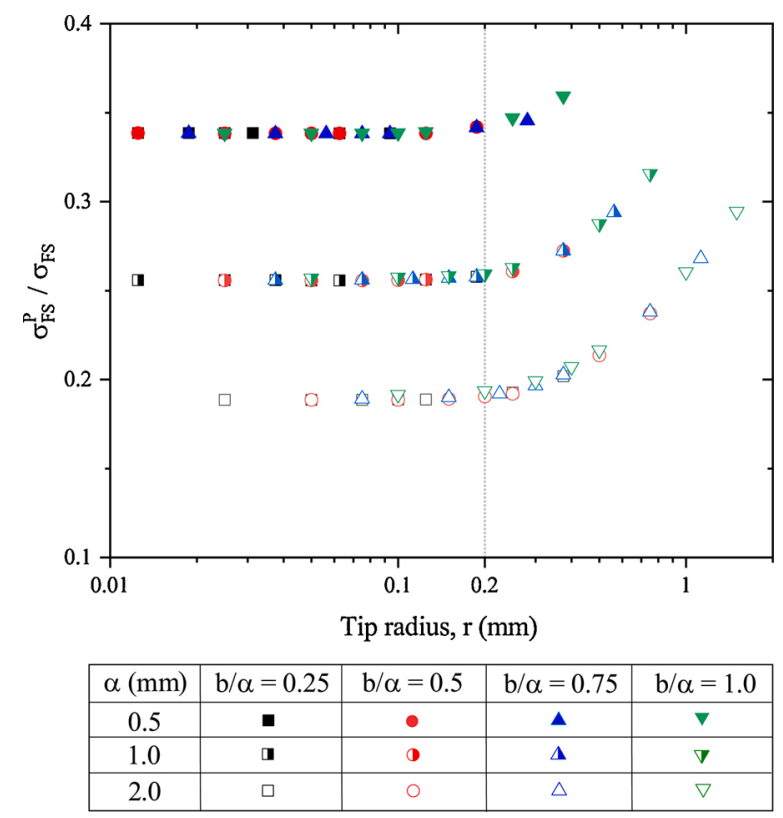

Fig. 17. In-air knock down factor as a function of pit radius for V-shaped pitted carbon steel specimens [64]. obtaining a pitting fatigue strength value at a certain number of cycles based on the experimental plain fatigue resistance for the same number of cycles. This procedure has been applied to the fatigue results presented in [64], where the in-air S-N curve of carbon steel plain and pitted specimens are included. Thus, Fig. 18 shows the laboratory test results for plain and pitted specimens and the estimated S-N curve made with present method.

In the same way, S-N curves for plain and pitted $12 \% \mathrm{Cr}$ steel specimens, as presented by Schönbauer [61], were used to evaluate the ability of the proposed technique to estimate S-N curves for pitted specimens (typical pit depths were $100 \mu \mathrm{m}$ ). Results are shown in Fig. 19.

As shown in Figs. 18 and 19, the estimated S-N curves fit very well with the experimental pitting corrosion fatigue S-N data and provide conservative estimations for the whole high and very high cycle fatigue range $\left(10^{6}-10^{9}\right.$ cycles).

\section{Discussion}

The present work simplifies the geometry of a 3D pit into a 2D pit. Although significant differences can arise when comparing $K_{t}$ for such cases, these differences are known to be smaller compared to the usual re-characterisation of the pit into a sharp crack, a common approach at the time of assessing fatigue life in the presence of corrosion pits [7]. This re-characterisation allows the application of linear elastic fracture mechanics (LEFM) tools for damage tolerance analysis, neglecting the crack initiation and short crack propagation stages and assuming the pit as a long crack. LEFM methods, although useful in a variety of application, are invalid for assessing the conditions for short crack propagation, which are extremely relevant to the characterisation of pit-to-crack transition and fatigue life from pits. Another important aspect is that this simplification yields into conservative estimations, e.g. the stress gradients of the $2 \mathrm{D}$ semi-ellipse is always higher than that of the 3D semi-ellipsoid.

In addition, the fatigue strength of components with stress raisers is $K_{t}$-dependent for relatively low values of $K_{t}$ and therefore the $K_{t}$ needs to be accurately calculated. On the other hand, the fatigue strength and life of components with severe stress concentration features is known to be unaffected by the $K_{t}$ and is highly affected by the pit depth [61], which was well captured by our model in Figs. 6, 14 and 15 .

For sharp pits (low $b / \alpha$ in Figs. 12 and 13, with $K_{t}>4$ in Fig. 14), on

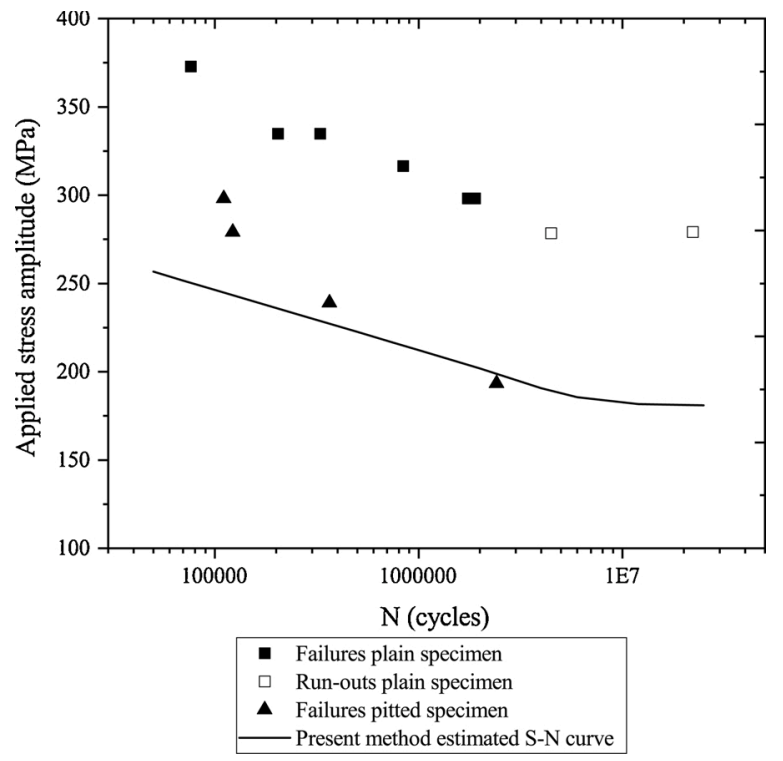

Fig. 18. Estimated S-N curve for carbon steel pitted specimens inside inert environment [64]. 


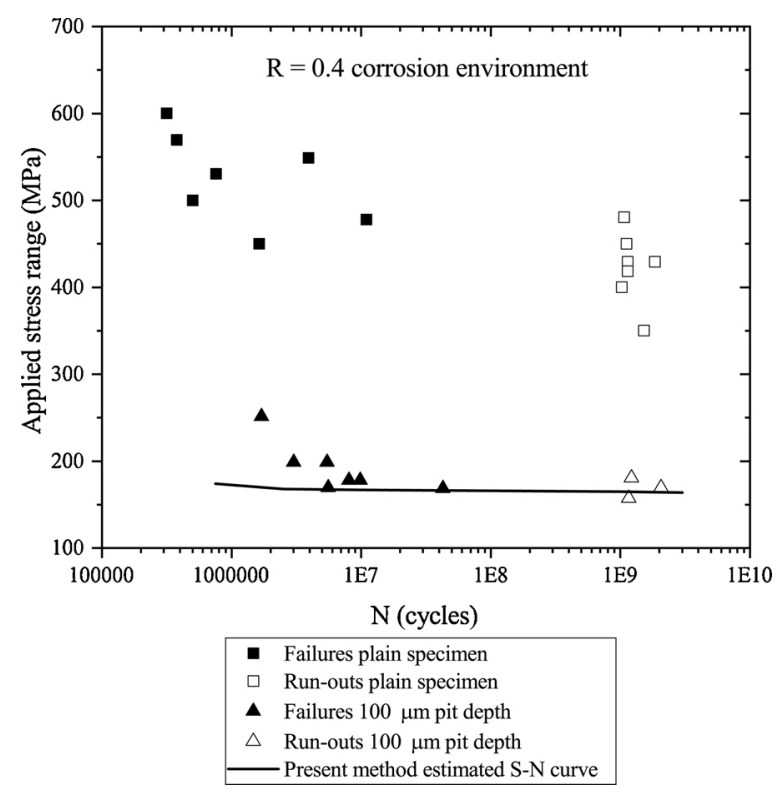

Fig. 19. Estimated S-N curve for $17-4 \mathrm{PH}$ stainless steel pitted specimens in $10,000 \mathrm{ppm} \mathrm{Cl}^{-}$solution [61].

the other hand, where a crack-like behaviour is expected, the fatigue strength breaks down reaching a minimum value and becoming nearly $K_{t}$-independent. In such cases, it is well known that the cracks that may initiate and propagate can albeit be arrested after reaching a certain length, giving rise to so-called non-propagating cracks [68]. That is why notch fatigue models are based on the concept of the 'process zone', where the general idea is that the plain specimen fatigue limit must be exceeded not only at the hot spot but also within some region ahead of the notch or critical volume. In practice, this is usually simplified to a critical distance [69] ahead of the stress concentration feature (e.g. notch, corrosion pit, weld pore, metallurgical inclusion, etc.). Thus, the analysis typically entails an elastic finite elements analysis for the evaluation of the stress at a distance $L / 2$ from the notch tip, where $L$ is the critical distance and is a material property. Typical values of $L / 2=0.1-0.15 \mathrm{~mm}$ in metallic materials. Using the critical distance method, it is straightforward to calculate the $2 \mathrm{D}$ and $3 \mathrm{D}$ stresses at $L / 2$ and evaluate the resistance to crack propagation for each case.

Differences between 2D and 3D stress levels ahead of the notch tip are significantly lower. For example, for a notch with $\alpha / b=5$, the differences between these stresses are small, within $15 \%$. Similar trends would be obtained if other aspect ratio $\alpha / b$ are analysed. This similarity in stress at distance $L / 2$ could be used to justify the use of the 2D model proposed in this work and to understand why the $2 \mathrm{D}$ model predicts reasonably well the fatigue failure of the real three-dimensional solid.

These two different behaviours are clearly shown in the classical Frost diagram [70] (Figs. 14 and 15). Therefore, from a fatigue strength and life estimation viewpoint, the stress concentration factor is only relevant for pits with low $K_{t}$ values. The cases analysed in Section 3.1 (Model validation) are for aspect ratios $\alpha / b=1.25$ [61] and $\alpha / b=2$ [60], which according to our finite element models, have a $K_{t}=3.8$ (2D) and $K_{t}=2.2$ (3D) and $K_{t}=5.3(2 \mathrm{D})$ and $K_{t}=2.46$ (3D), respectively, therefore with relative high stress concentration factors, where our methodology was able to provide results with acceptable accuracy.

\section{Conclusions}

In this work, the ability of short fatigue cracks to propagate from corrosion pits (i.e. pit-to-crack transition) has been studied through a micromechanical model for the first time. The pit geometry, crack and microstructural barriers are modelled with distributed dislocations. The model allows the effect of local pit shape to be accounted for and considers the effect of the environment on short and long crack growth by means of the Kitagawa-Takahashi diagram of the material in the specific environment.

The application of the model to pitting corrosion fatigue is first validated using available experimental data in the literature. Pitting corrosion fatigue strength and, subsequently, S-N curves were estimated. Carbon and stainless steels in different environments were analysed and the S-N curves of the material were estimated, with reasonable agreement (typical differences between experimental results and simulations within $20 \%$ with maximum differences around $30 \%$ ). Although further validation is required for extensive industrial applications, this tool proves to be useful for studying the influence of pit geometry, material and environmental variables in fatigue design curves.

The minimum NDE resolution that is necessary for damage tolerance arguments based on defect acuity has also been discussed. The proposed tool shows to be valuable to assess the impact of resolving defect shape and acuity in fatigue calculations and reduce the excessive conservatism inherent in approaches based on fracture mechanics.

\section{Data availability}

The raw/processed data required to reproduce these findings cannot be shared at this time as the data also forms part of an ongoing study. Please contact the correspoding author for getting access to the DDT software and the generative design tool.

\section{CRediT authorship contribution statement}

J.A. Balbín: Software, Validation, Formal analylsis, Investigation, Writing - Original Draft. V. Chaves: Conceptualization, Resources, Writing - Review \& Editing. N.O. Larrosa: Conceptualization, Formal analysis, Writing - Review \& Editing, Supervision

\section{Conflicts of interest}

None declared.

\section{Declaration of Competing Interest}

The authors report no declarations of interest.

\section{Acknowledgements}

The authors would like to thank the Spanish Ministry of Education for its financial support through grantDPI2014-56904-P andDPI201784788-P. Dr N. Larrosa would like to acknowledge the funding provided by the UK Engineering and Physical Sciences Research Council under grant no. EP/S012362/1.

\section{References}

[1] R. Heidersbach, Metallurgy and corrosion control in oil and gas production. Wiley Series in Corrosion, John Wiley \& Sons, 2010, https://doi.org/10.1002/ 9780470925782.

[2] P.R. Roberge, Corrosion Inspection and Monitoring, vol. 2, 2007.

[3] S. Caines, F. Khan, J. Shirokoff, Analysis of pitting corrosion on steel under insulation in marine environments, J. Loss Prev. Process Ind. 26 (6) (2013) 1466-1483, https://doi.org/10.1016/j.jlp.2013.09.010.

[4] L.L. Shreir (Ed.), Corrosion, vol. 2, Newnes-Butterworths, London, 1976.

[5] R.E. Melchers, Progress in developing realistic corrosion models, Struct. Infrastruct. Eng. 14 (7) (2018) 843-853, https://doi.org/10.1080/15732479.2018.1436570.

[6] A. Turnbull, The environmentally small/short crack growth effect: current understanding, Corros. Rev. 30 (1-2) (2012) 1-17.

[7] N.O. Larrosa, R. Akid, R.A. Ainsworth, Corrosion-fatigue: a review of damage tolerance models, Int. Mater. Rev. 63 (5) (2018) 283-308, https://doi.org/ 10.1080/09506608.2017.1375644.

[8] H. Mansoori, R. Mirzaee, F. Esmaeilzadeh, A. Vojood, A.S. Dowrani, Pitting corrosion failure analysis of a wet gas pipeline, Eng. Fail. Anal. 82 (2017) 16-25, https://doi.org/10.1016/j.engfailanal.2017.08.012. 
[9] M.V. Biezma, M.A. Andrés, D. Agudo, E. Briz, Most fatal oil \& gas pipeline accidents through history: a lessons learned approach, Eng. Fail. Anal. 110 (2020) 104446, https://doi.org/10.1016/j.engfailanal.2020.104446.

[10] Petroleum and Natural Gas Industries - Fixed Steel Offshore Structures, Standard, International Organization for Standardization, 2007.

[11] DNV, DNVGL-RP-C203 Fatigue Design of Offshore Steel Structures, Recommended Practice, Det Norske Veritas, Oslo, Norway, 2016.

[12] AENOR, Asociación Española de Normalización y Certificación, UNE-EN 13103: Railway Applications - Wheelsets and Bogies, Standard, 2002.

[13] AENOR, Asociación Española de Normalización y Certificación, UNE-EN 13104: Railway Applications - Wheelsets and Bogies - Powered Axles - Design Method, Standard, 2009.

[14] AENOR, Asociación Española de Normalización y Certificación, BS-EN 13261: Railway Applications - Wheelsets and Bogies - Axles - Product Requirements, Standard, 2003.

[15] Office of Nuclear Regulatory Research, NUREG/CR-6909: Effect of LWR Water Environments on the Fatigue Life of Reactor Materials, Standard, 2018.

[16] ASME, ASME BPVC Rules for Construction of Nuclear Facility Components, Standard, The American Society of Mechanical Engineers, New York, USA, 2019.

[17] N.O. Larrosa, R.A. Ainsworth, R. Akid, P.J. Budden, C.M. Davies, I. Hadley, D. R. Tice, A. Turnbull, S. Zhou, 'Mind the gap' in fitness-for-service assessment procedures-review and summary of a recent workshop, Int. J. Press. Vessels Piping 158 (2017) 1-19, https://doi.org/10.1016/j.ijpvp.2017.09.004.

[18] D.S. Hoddinott, Railway axle failure investigations and fatigue crack growth monitoring of an axle, Proc. Inst. Mech. Eng. Part F: J. Rail Rapid Transit 218 (4) (2004) 283-292, https://doi.org/10.1243/0954409043125897.

[19] Transportation Safety Board of Canada, Main Track Derailment: Canadian National Train No. G-894-31-14. Railway Investigation Report R01Q0010, 2001. Tech. Rep.

[20] N.O. Larrosa, P. Lopez-Crespo, R.A. Ainsworth, An efficient procedure for reducing in-line-inspection datasets for structural integrity assessments, Theor. Appl. Fract. Mech. 93 (2018) 79-87, https://doi.org/10.1016/j.tafmec.2017.07.005.

[21] T.S. Barber, P.D. Wilcox, A.D. Nixon, Optimization of element length for imaging small volumetric reflectors with linear ultrasonic arrays, AIP Conf. Proc. 1706 (1) (2016) 020016, https://doi.org/10.1063/1.4940462.

[22] C. Holmes, B.W. Drinkwater, P.D. Wilcox, Post-processing of the full matrix of ultrasonic transmit-receive array data for non-destructive evaluation, NDT E Int. 38 (8) (2005) 701-711, https://doi.org/10.1016/j.ndteint.2005.04.002, publisher: Elsevier Other: in press.

[23] N. Brierley, T. Tippetts, P. Cawley, Data fusion for automated non-destructive inspection, Proc. R. Soc. A: Math. Phys. Eng. Sci. 470 (2167) (2014) 20140167, https://doi.org/10.1098/rspa.2014.0167.

[24] A. Velichko, L. Bai, B.W. Drinkwater, Ultrasonic defect characterization using parametric-manifold mapping, Proc. R. Soc. A: Math. Phys. Eng. Sci. 473 (2202) (2017) 20170056, https://doi.org/10.1098/rspa.2017.0056.

[25] M.C. Remillieux, D. Kaoumi, Y. Ohara, M.A.S. Geesey, L. Xi, R. Schoell, C.R. Bryan, D.G. Enos, D.A. Summa, T.J. Ulrich, B.E. Anderson, Z. Shayer, Detecting and imaging stress corrosion cracking in stainless steel, with application to inspecting storage canisters for spent nuclear fuel, NDT E Int. 109 (2020) 102180, https://doi. org/10.1016/j.ndteint.2019.102180.

[26] ASME, ASME B31G Manual for Determining the Remaining Strength of Corroded Pipelines, Standard, The American Society of Mechanical Engineers, New York, USA, 2012.

[27] API, API 579-1 Fitness for Service, Standard, American Petroleum Institute, Washington, USA, 2016.

[28] DNV, DNVGL-RP-F-101 Corroded Pipelines, Recommended Practice, Det Norske Veritas, Oslo, Norway, 2016.

[29] J.T. Burns, J.M. Larsen, R.P. Gangloff, Effect of initiation feature on microstructure-scale fatigue crack propagation in Al-Zn-Mg-Cu, Int. J. Fatigue 42 (2012) 104-121, https://doi.org/10.1016/j.ijfatigue.2011.08.001.

[30] S. Beretta, F. Sangalli, J. Syeda, D. Panggabean, J. Rudlin, RAAI Project: lifeprediction and prognostics for railway axles under corrosion-fatigue damage, Proc. Struct. Integr. 4 (2017) 64-70, https://doi.org/10.1016/j.prostr.2017.07.010.

[31] B.T. Lu, J.L. Luo, P.R. Norton, H.Y. Ma, Effects of dissolved hydrogen and elastic and plastic deformation on active dissolution of pipeline steel in anaerobic groundwater of near-neutral pH, Acta Mater. 57 (1) (2009) 41-49, https://doi.org/ 10.1016/j.actamat.2008.08.035.

[32] A. Nicolas, N.E.C. Co, J.T. Burns, M.D. Sangid, Predicting fatigue crack initiation from coupled microstructure and corrosion morphology effects, Eng. Fract. Mech. 220 (2019) 106661, https://doi.org/10.1016/j.engfracmech.2019.106661.

[33] G.M. Castelluccio, D.L. McDowell, Mesoscale modeling of microstructurally small fatigue cracks in metallic polycrystals, Mater. Sci. Eng.: A 598 (2014) 34-55, https://doi.org/10.1016/j.msea.2014.01.015.

[34] A. Navarro, E.R. De los Rios, Short and long fatigue crack growth: a unified model, Philos. Mag. A 57 (1) (1988) 15-36, https://doi.org/10.1080/ 01418618808204496.

[35] K.J. Miller, The two thresholds of fatigue behaviour, Fatigue Fract. Eng. Mater. Struct. 16 (9) (1993) 931-939, https://doi.org/10.1111/j.1460-2695.1993. tb00129.x.

[36] J. Andersson, The influence of grain size variation on metal fatigue, Int. J. Fatigue 27 (8) (2005) 847-852, https://doi.org/10.1016/j.ijfatigue.2004.11.007.

[37] E.R. De los Rios, M. Trull, A. Levers, Modelling fatigue crack growth in shot-peened components of al 2024-T351, Fatigue Fract. Eng. Mater. Struct. 23 (8) (2000) 709-716, https://doi.org/10.1046/j.1460-2695.2000.00287.x.

[38] V. Chaves, A. Navarro, Application of a microstructural model for predicting notch fatigue limits under mode I loading, Int. J. Fatigue 31 (5) (2009) 943-951, https:// doi.org/10.1016/j.ijfatigue.2008.09.009.
[39] V. Chaves, A. Navarro, Fatigue limits for notches of arbitrary profile, Int. J. Fatigue 48 (2013) 68-79, https://doi.org/10.1016/j.ijfatigue.2012.10.004.

[40] N.O. Larrosa, A. Navarro, V. Chaves, Calculating fatigue limits of notched components of arbitrary size and shape with cracks growing in Mode I, Int. J. Fatigue 74 (2015) 142-155, https://doi.org/10.1016/j.ijfatigue.2015.01.002.

[41] N.O. Larrosa, V. Chaves, A. Navarro, R.A. Ainsworth, Application of the microstructural finite element alternating method to assess the impact of specimen size and distributions of contact/residual stress fields on fatigue strength, Comput. Struct. 179 (2017) 15-26, https://doi.org/10.1016/j.compstruc.2016.10.011.

[42] W. Zhang, X. Wang, H. Chen, T. Zhang, J. Gong, Microstructural damage prior fatigue loading, Theor. Appl. Fract. Mech. 103 (2019) 102269, https://doi.org/ 10.1016/j.tafmec.2019.102269.

[43] D.L. McDowell, K. Gall, M.F. Horstemeyer, J. Fan, Microstructure-based fatigue modeling of cast A356-T6 alloy, Eng. Fract. Mech. 70 (1) (2003) 49-80, https:// doi.org/10.1016/S0013-7944(02)00021-8.

[44] E.R. De los Rios, X.D. Wu, K.J. Miller, A micro-mechanics model of corrosionfatigue crack growth in steels, Fatigue Fract. Eng. Mater. Struct. 19 (11) (1996) 1383-1400, https://doi.org/10.1111/j.1460-2695.1996.tb00174.x.

[45] K.J. Miller, R. Akid, The application of microstructural fracture mechanics to various metal surface states, Proc. R. Soc. Lond. Ser. A: Math. Phys. Eng. Sci. 452 (1949) (1996) 1411-1432, https://doi.org/10.1098/rspa.1996.0072.

[46] D.A. Hills, P.A. Kelly, D.N. Dai, A.M. Korsunsky, Solution of Crack Problems, The Distributed Dislocation Technique, Kluwer Academic Publishers, 1996, https://doi. org/10.1007/978-94-015-8648-1.

[47] H. Kitagawa, S. Takahashi, Applicability of fracture mechanics to very small cracks or the cracks in the early stage, Proceedings 2nd International Conference on Mechanical Behavior of Materials (1976) 627-631.

[48] A. Navarro, E.R. De los Rios, An alternative model of the blocking of dislocations at grain boundaries, Philos. Mag. A 57 (1) (1988) 37-42, https://doi.org/10.1080/ 01418618808204497.

[49] A. Navarro, E.R. De Los Rios, Fatigue crack growth modelling by successive blocking of dislocations, Proc. R. Soc. 437 (1900) (1992) 375-390. http://www.jst or.org/stable/52204.

[50] B.A. Bilby, A.H. Cottrell, K.H. Swinden, The spread of plastic yield from a notch, Proc. R. Soc. Lond. Ser. A Math. Phys. Sci. 272 (1350) (1963) 304-314, https://doi. org/10.1098/rspa.1963.0055.

[51] J. Weertman, J.R. Weertman, Elementary Dislocation Theory, Macmillan Series in Materials Science, Macmillan, 1964.

[52] C. Vallellano, A. Navarro, J. Domínguez, Compact formulation for modelling cracks in infinite solids using distributed dislocations, Philos. Mag. A 82 (1) (2002) 81-92, https://doi.org/10.1080/01418610208239998.

[53] D. Taylor, A mechanistic approach to critical-distance methods in notch fatigue, Fatigue Fract. Eng. Mater. Struct. 24 (4) (2001) 215-224, https://doi.org/ 10.1046/j.1460-2695.2001.00401.x.

[54] M.H.E. Haddad, T.H. Topper, K.N. Smith, Prediction of non propagating cracks, Eng. Fract. Mech. 11 (3) (1979) 573-584, https://doi.org/10.1016/0013-7944(79) 90081-X.

[55] M.D. Chapetti, Fatigue propagation threshold of short cracks under constant amplitude loading, Int. J. Fatigue 25 (12) (2003) 1319-1326, https://doi.org/ 10.1016/S0142-1123(03)00065-3.

[56] C. Vallellano, A. Navarro, J. Domínguez, Fatigue crack growth threshold conditions at notches. Part I: theory, Fatigue Fract. Eng. Mater. Struct. 23 (2) (2000) 113-121, https://doi.org/10.1046/j.1460-2695.2000.00257.x.

[57] N.O. Larrosa, A dislocation based method using generative algorithms to model notch geometries: determination of Mode I SIFs, Eng. Fract. Mech. 127 (2014) $327-335$.

[58] N.O. Larrosa, M. Treifi, R.A. Ainsworth, Rapid parametric analysis of SEN(T) specimens using algorithmic modelling: evaluation of strain energy density and notch stress intensity factors, Mater. Des. 85 (2015) 771-777.

[59] EPRI, Program on Technology Innovation: Development of a Corrosion-Fatigue Prediction Methodology for Steam Turbines. Experimental Results 2009-2010, Tech. Rep. 1023196, Electric Power Research Institute, Palo Alto, CA, 2011.

[60] G. Härkegård, Short-crack modelling of the effect of corrosion pits on the fatigue limit of $12 \%$ Cr steel, Fatigue Fract. Eng. Mater. Struct. 38 (9) (2015) 1009-1016, https://doi.org/10.1111/ffe.12305.

[61] B.M. Schönbauer, S.E. Stanzl-Tschegg, A. Perlega, R.N. Salzman, N.F. Rieger, A. Turnbull, S. Zhou, M. Lukaszewicz, D. Gandy, The influence of corrosion pits on the fatigue life of 17-4PH steam turbine blade steel, Eng. Fract. Mech. 147 (2015) 158-175, https://doi.org/10.1016/j.engfracmech.2015.08.011.

[62] EPRI, Program on Technology Innovation: Development of a Corrosion-Fatigue Prediction Methodology for Steam Turbines. AISI 403/410 3002005107, Electric Power Research Institute, Palo Alto, CA, 2015.

[63] K. van der Walde, J.R. Brockenbrough, B.A. Craig, B.M. Hillberry, Multiple fatigue crack growth in pre-corroded 2024-T3 aluminum, Int. J. Fatigue 27 (10) (2005) 1509-1518, https://doi.org/10.1016/j.ijfatigue.2005.06.026.

[64] S. Li, R. Akid, Corrosion fatigue life prediction of a steel shaft material in seawater, Eng. Fail. Anal. 34 (2013) 324-334.

[65] S.A. Barter, L. Molent, Fatigue cracking from a corrosion pit in an aircraft bulkhead, Eng. Fail. Anal. 39 (2014) 155-163, https://doi.org/10.1016/j. engfailanal.2014.01.020.

[66] A. Turnbull, L. Wright, L. Crocker, New insight into the pit-to-crack transition from finite element analysis of the stress and strain distribution around a corrosion pit, Corros. Sci. 52 (4) (2010) 1492-1498, https://doi.org/10.1016/j. corsci.2009.12.004. 
[67] N.O. Larrosa, M. Chapetti, R.A. Ainsworth, Fatigue life estimation of pitted specimens by means of an integrated fracture mechanics approach. Vol. 3: Design and Analysis of Pressure Vessels and Piping Conference, ASME, 2016.

[68] V. Chaves, C. Madrigal, A. Navarro, Non-propagating cracks in notched components at the fatigue limit analysed with a microstructural model, Theor Appl. Fract. Mech. 95 (2018) 119-126, https://doi.org/10.1016/j. tafmec.2018.02.008.
[69] D. Taylor, Geometrical effects in fatigue: a unifying theoretical model, Int. J. Fatigue 21 (5) (1999) 413-420, https://doi.org/10.1016/S0142-1123(99)00007. 9.

[70] N.E. Frost, Non-propagating cracks in Vee-notched specimens subjected to fatigue loading, Aeronaut. Q. 8 (1) (1957) 1-20. 